\title{
Impact of road traffic on air quality at two locations in Kuwait
}

\author{
E. Al-Bassam ${ }^{1}$, V. Popov ${ }^{2} \&$ A. Khan ${ }^{1}$ \\ ${ }^{1}$ Environment and Urban Development Division, \\ Kuwait Institute for Scientific Research, Kuwait \\ ${ }^{2}$ Wessex Institute of Technology, Southampton, UK
}

\begin{abstract}
Kuwait having one of the highest GDP and the least fuel price provides ideal opportunity for ownership of motorized vehicles. Weather has also a major role in this issue where in long summer (lasting about nine months), temperature sores to nearly $50{ }^{\circ} \mathrm{C}$ very often and in short winter it drops to single digit value in early mornings and nights. The road transport is vital for the local inhabitants as the sole means of transport (commuting and transporting goods).

In the last decade, motorized road vehicle fleet has grown significantly bringing unprecedented mobility to the burgeoning population. With the growth of vehicles, the fuel consumption has also increased. Motor vehicles are a critical source of urban air pollution $\left(\mathrm{PM}_{10}, \mathrm{CO}, \mathrm{CO}_{2}, \mathrm{NOx}, \mathrm{O}_{3}, \mathrm{SO}_{2}\right.$ and VOCs). Air pollution is a serious health problem and accounts for hundred of millions of dollars for health care and welfare cost.

This paper focuses on environmental impact of road transport on the air quality around two selected schools for a period of two weeks each using an air pollution monitoring station which continuously recorded various pollutants' concentrations and meteorological variables in five minute intervals. The results show that for both sites during the weekdays, the measured pollutants emitted from the road traffic next to the selected schools, such as carbon monoxide (CO) and nitrogen dioxide $\left(\mathrm{NO}_{2}\right)$, were always under the allowable limits for Kuwaiti air quality standards, except for a single occurrence for $\mathrm{NO}_{2}$ concentration at morning hours for the governmental school. On the other hand, the values of non-methane hydrocarbon pollutants were found to be several times above the Kuwaiti air quality standards throughout the investigated period. The suspended particulates $\left(\mathrm{PM}_{10}\right)$ concentrations have twice exceeded the limits of Kuwaiti air quality standards.
\end{abstract}

Keywords: congestion, pollutants, air quality standards, schools. 


\section{Introduction}

The transport sector is considered a major cause of the high level of air pollution in urban regions which affects the environment and ultimately, the human health. Air quality expert group has shown that pollutants emitted from the traffic have a big effect on human health [1]. A German paper mentioned that based on many studies it was shown that particulate matter causes damage to health and is responsible for increased rates of mortality and to lung cancer [2]. Amato et al. [3] mentioned that the frequency of allergic respiratory symptoms is higher in urban areas due to vehicle traffic than in rural areas. A Dutch study found that respiratory disorders of 632 children aged 7 to 11 worsened as air pollution increased [4]. Guo et al. [5] have reported that over 331,000 middle school children in Taiwan found that traffic related air pollution especially, carbon monoxide and nitrogen dioxides, were positively associated with the prevalence of asthma.

According to the Ministry of Education (MOE) in Kuwait statistical data and Ministry of Planning statistics, the school buses are serving approximately 17 to $18 \%$ of students in the government schools. Based on 2003/2004 statistics, there are 23,302 students using buses out of 131,597 total students. The rest of students mostly depend on private transportation.

\section{Study area}

This study deals with two schools located in flat and homogeneous terrain with out any major local air pollution emission sources except road traffic. One of these schools is located next to Muthana road at Hawalli Area and the other school is located next to Road 57 at Mishref Area. Muthana road is surrounded by many residential buildings, grocery stores, bookshops and schools. The school is private and has an area of $67,000 \mathrm{~m}^{2}$. It is surrounded by four roads, from the east Muthana major road and the main gate for the school opens at this road for secondary and middle school students, teachers' cars and buses. At the north, there is a narrow road with one lane having traffic flow in both directions but from 6:00 to $9: 00 \mathrm{hr}$ and 13:00 to $15: 00 \mathrm{hr}$, it accommodates only unidirection traffic flow. This road intersects with Muthana two-lane road without traffic signals. In this narrow road the gate of the school opens for elementary class children. There is a narrow lane in the west that has another gate available for elementary and kindergarten students. From south, there is another narrow lane parallel to a main freeway called Fourth Ring Road. The Fourth Ring Road is a vital and essential freeway consisting of three lanes for each side and the traffic volume of the road is extremely high at weekdays. The other school at Mishref is a governmental school with no school buses at morning or afternoon time for students. It is surrounded by Road 57 from north and from the east there is another school under construction and other governmental schools. From west and south, the school is surrounded by a street with two lanes having traffic in each direction. The school area is $18,000 \mathrm{~m}^{2}$ and has a parking in the front of the entrance of the school gate. 


\section{Monitoring}

Air quality and weather data were recorded at sampling intervals of 5 minutes from 18 February to 18 March 2006 for both sites by Kuwait Institute for Scientific Research (KISR), using its mobile air monitoring station. The measured data included the concentration of different pollutants such as methane, $\mathrm{CH}_{4}$ and non methane hydrocarbons, nitrogen oxide (NO), nitrogen dioxide $\left(\mathrm{NO}_{2}\right)$, carbon monoxide $(\mathrm{CO})$ and $\mathrm{PM}_{10}$. In addition, the measured data included wind speed, wind direction, solar radiation, humidity and ambient temperature. The monitoring station was parked on Muthana road almost $100 \mathrm{~m}$ from the main gate of the selected private school. Later it has been moved to the other location at Mishref area next to the governmental school entrance. A road side counter was used to register the number of cars on the roads around the chosen schools for every 15 minutes throughout this study period. The measurements were taken during the months of February and March including the weekdays, weekends and national holidays.

\section{Methodology}

Air quality and weather data were recorded at sampling intervals of 5 minutes by Kuwait Institute for Scientific Research (KISR) air monitoring station as shown in figure 3 for two weeks. The measured data included the concentration of different pollutants such as carbon monoxide $(\mathrm{CO})$, carbon dioxide $\left(\mathrm{CO}_{2}\right)$, methane $\left(\mathrm{CH}_{4}\right)$ and non-methane hydrocarbons, nitrogen oxides $\left(\mathrm{NO}_{\mathrm{x}}\right)$, nitrogen dioxide $\mathrm{NO}_{2}$, and suspended particulates $\left(\mathrm{PM}_{10}\right)$. In addition, the measured data included wind speed, wind direction, solar radiation and ambient temperature. The monitoring station was parked in Hawalli area next to the private school for two weeks approximately then it moved to Mishref area next to the governmental school entrance. A traffic counter was used to record the number of cars in the roads next to the selected schools for every 15 minutes throughout the study period. The measurements were taken during February and March 2006 including weekdays and weekend holidays.

\section{Discussion and results}

\subsection{Traffic}

The hourly average weekday and weekend traffic flow profiles are shown in Figures 1 and 2 for the roads next to the selected schools. The profile of the traffic indicates two distinct peaks for both sites during the working days which are related to the schools opening time and employees going to work and noon time returning from schools and work for the students and employees respectively. At weekends there are no conspicuous peaks, and traffic flow gradually increases followed by slight decrease at afternoon time, then with minor increase in the evening. 
During peak traffic times, there was larger traffic flow near the governmental school than private school due to the occurrence of many schools and less traffic network cluster in Mishref area.

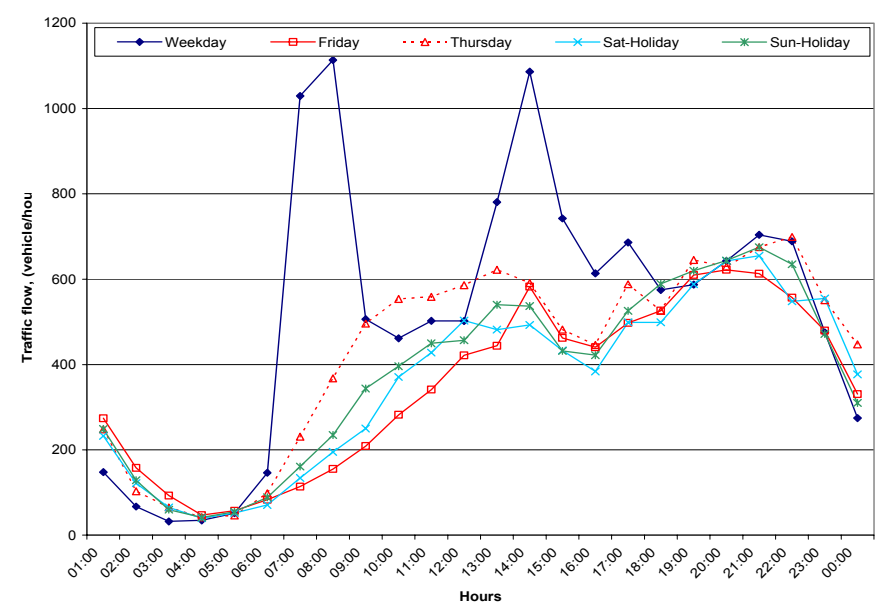

Figure 1: Hourly traffic flow for weekdays and weekend days next to the private school.

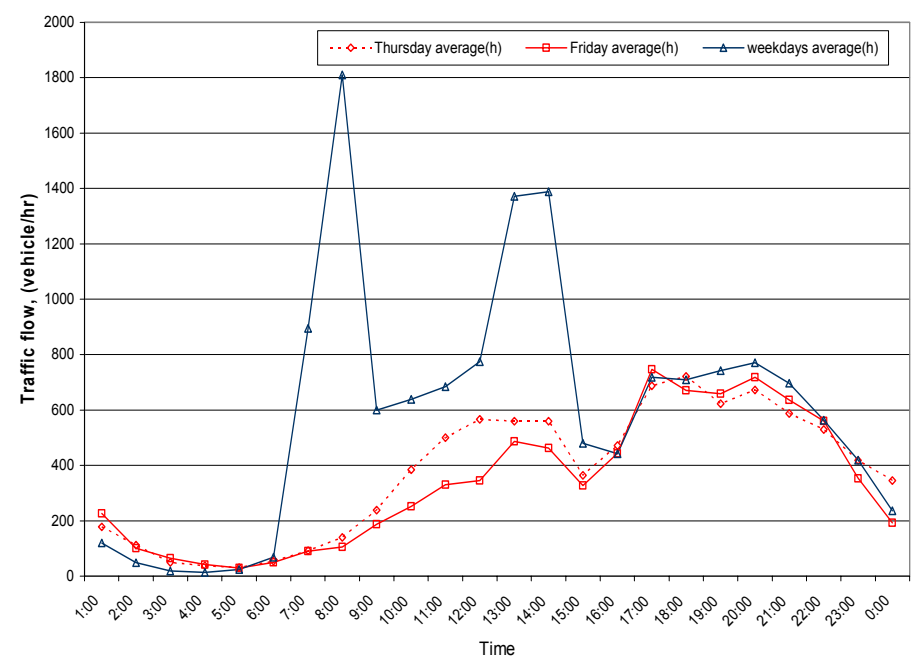

Figure 2: Hourly traffic flow for weekdays and weekend days next to the governmental school.

\subsection{Measured pollutants}

The concentrations of primary pollutants such as $\mathrm{CO}, \mathrm{NO}_{2}$ and $\mathrm{PM}_{10}$ were recorded from 18 February to 18 March 2006 for both sites. The profile for $\mathrm{CO}$ 
concentration has distinct variation, the highest concentration recorded in the morning hours and the second highest in the afternoon hour as shown in Figs. 3 and 4 for private and governmental school respectively.

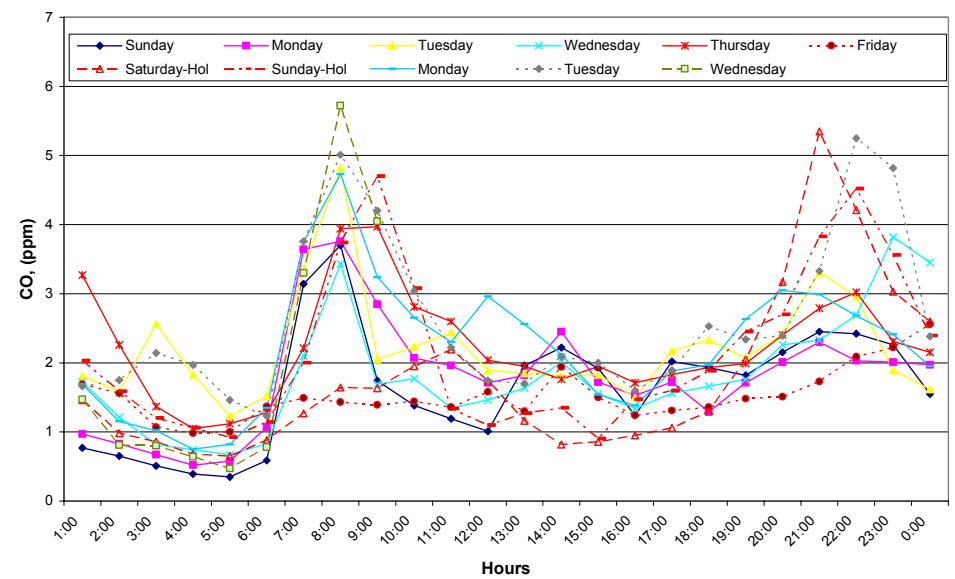

Figure 3: Average daily variation of $\mathrm{CO}$ emissions next to the private school from 19 February to 1 March 2006.

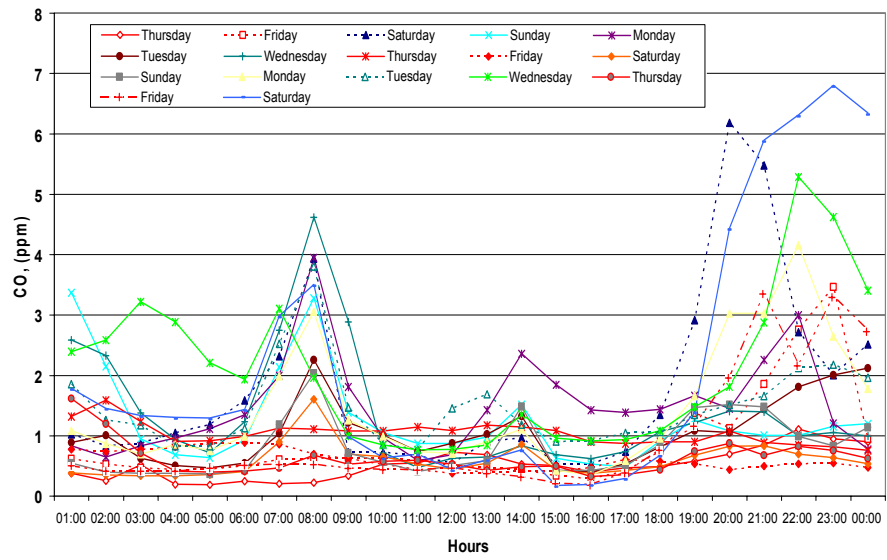

Figure 4: Average daily variation of $\mathrm{CO}$ emissions next to the governmental school from 2-18 March 2006.

On the contrary to traffic flow, $\mathrm{CO}$ concentrations were slightly higher at private school than the governmental school in morning opening hours and noon closing hours with the exception of late night hours, where high concentrations were recorded at the governmental school. The high concentrations were due to traffic congestion, road layout, local terrain and prevailing meteorological conditions. There is a conspicuous weekend effect reflecting low concentrations on Thursdays and Fridays at both sites. 


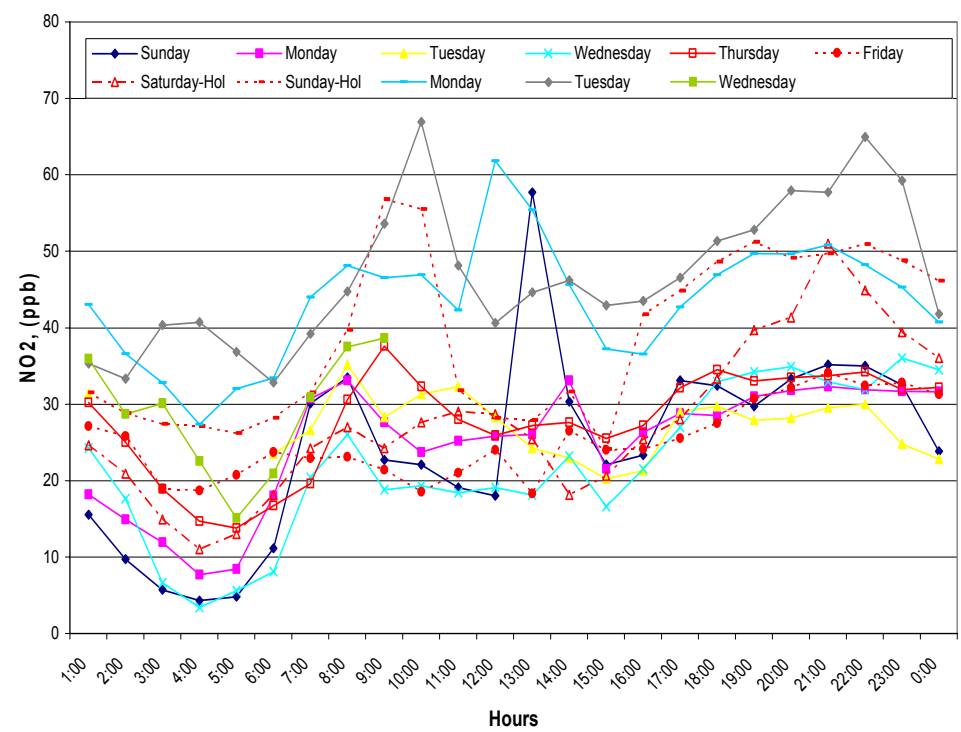

Figure 5: Average daily variation of $\mathrm{NO}_{2}$ emissions next to the private school from 19 February to 1 March 2006.

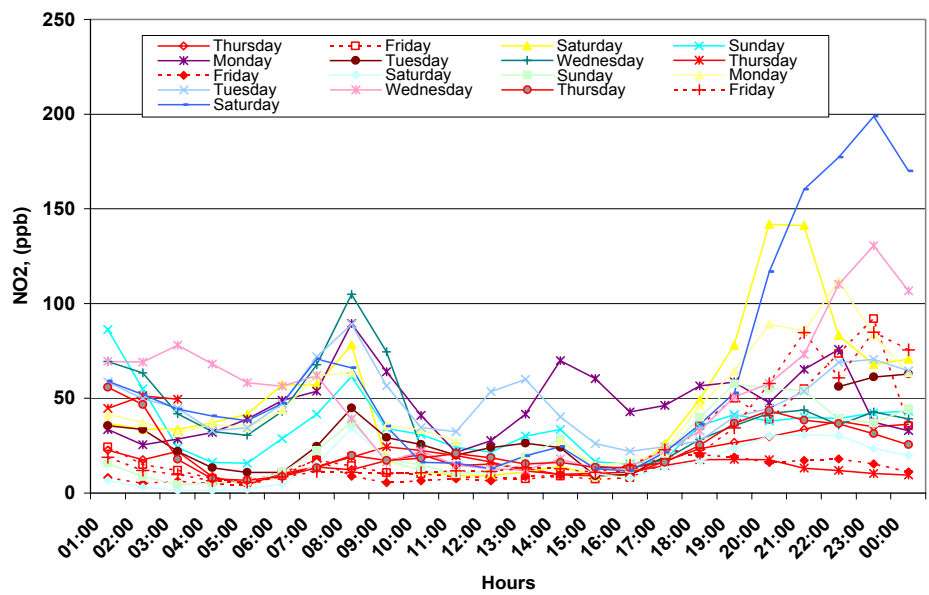

Figure 6: Hourly variation of $\mathrm{NO}_{2}$ for different days near the governmental school.

Figs. 5 and 6 show the $\mathrm{NO}_{2}$ profile for the two sites. The lowest concentrations of $\mathrm{NO}_{2}$ were recorded on Thursday and Friday clearly indicating low traffic flow on weekend at both sites. $\mathrm{NO}_{2}$ is a major constituent of $\mathrm{NOx}$ and $\mathrm{NOx}$ profiles are identical to $\mathrm{NO}_{2}$ with a multiple factor. $\mathrm{NO}_{2}$ and $\mathrm{NOx}$ concentrations were higher at government school than private school, reflecting the traffic density, where the influence of traffic flow was not that much 
pronounced (Lee et al., 2003). The diurnal trend of $\mathrm{NO}_{2}$ was obvious from Figs. 5 and 6 showing an increase in morning hours followed by another smaller peak in the afternoon and later another increase in evening, depicting shopping and other recreational activities at both sites.

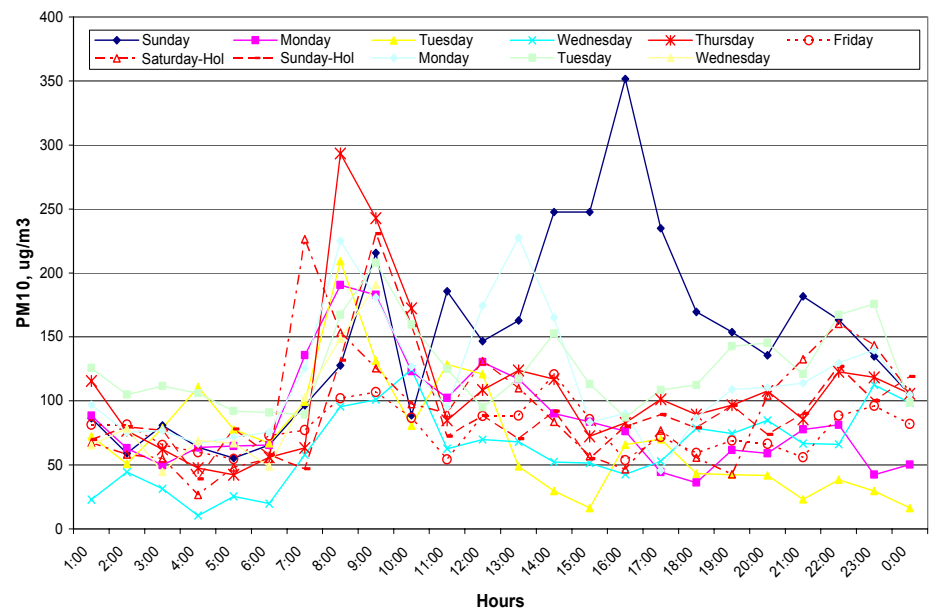

Figure 7: Hourly variation of $\mathrm{PM}_{10}$ for different days near the private school.

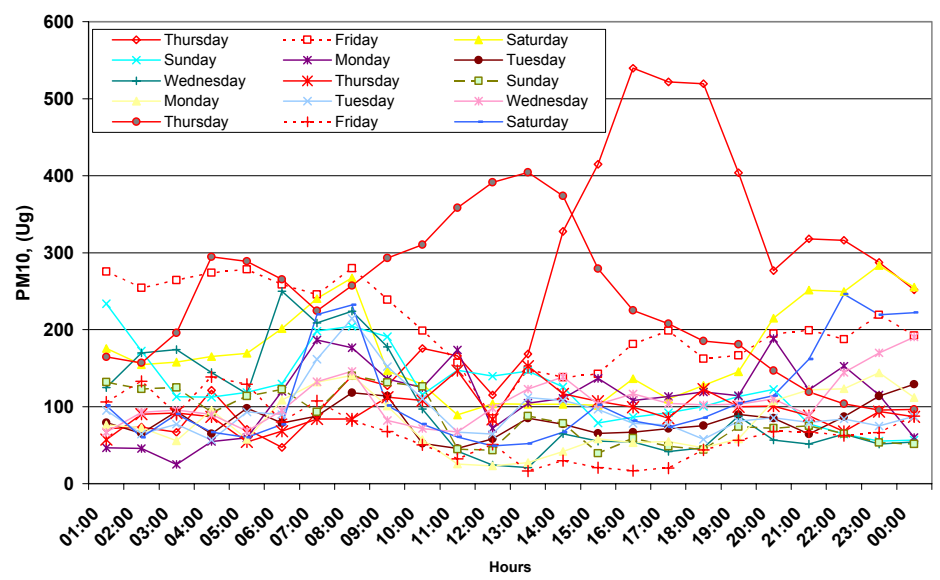

Figure 8: Hourly variation of $\mathrm{PM}_{10}$ for different days near the governmental school.

The concentration of particulate matter, $\mathrm{PM}_{10}$ is presented in Figs. 7 and 8 for private and government schools. $\mathrm{PM}_{10}$ concentration are dependent on prevailing meteorological conditions due to arid climate in the State of Kuwait and existence of high frequency of dust storms that overwhelmingly suppressed the contribution of traffic emission as obvious from Fig. 8. Fig. 7 shows the diurnal 
variation of $\mathrm{PM}_{10}$ concentrations representing high activities in morning hours of week days.

\subsection{Air quality}

All the measured pollutants' concentrations in the vicinity of the selected schools for a period of four weeks were compared with the allowable levels according to Kuwait's air quality standards. The Air Quality Standards (A.A.Q) in the residential areas for Kuwait, Federal US and California states are presented in Table 1. The concentration level of $\mathrm{CO}, \mathrm{NO}_{2}$, and $\mathrm{PM}_{10}$ pollutants are shown in Figures 3 to 8 . The $\mathrm{CO}$ concentrations are always under the allowable limits. The average NMHC concentrations are always above the specified limits as shown in figure 9. $\mathrm{NO}_{2}$ concentration had exceeded the allowable limits 15 times during the study period near the governmental school. The $\mathrm{NO}_{2}$ exceedances are mainly due to road traffic since these values were associated with the increase of $\mathrm{CO}$ levels. Regarding $\mathrm{PM}_{10}$ levels it has exceeded the limits of A.A.Q (on two occassions) during the time of recording.

Table 1: The hourly air quality standards for Kuwait, Federal US and California State.

\begin{tabular}{|c|c|c|c|}
\hline Pollutant & Kuwaiti Standards & $\begin{array}{c}\text { Federal } \\
\text { Standards }\end{array}$ & EU standards \\
\hline Ozone $(\mathrm{ppb}),\left[\mu \mathrm{g} / \mathrm{m}^{3}\right]$ & $80,[157]$ & $120,[235]$ & $90,[180]^{*}$ \\
\hline [ppm] & 30 & 35 & $10^{* *} \mathrm{mg} / \mathrm{m}^{3}$ \\
\hline [ppb] & 100 & - & $200^{* * *} \mu \mathrm{g} / \mathrm{m}^{3}$ \\
\hline $\mathrm{PM}_{10} \quad\left[\mu \mathrm{g} / \mathrm{m}^{3}\right]$ & 350 (24 hours) & 150 (24 hours) & 50 (24 hours) \\
\hline NMHC [ppm] & $\begin{array}{c}0.24 \text { for a period of } \\
3 \text { hours }(6-9 \text { AM) }\end{array}$ & - & - \\
\hline
\end{tabular}

Source: [6].

\section{Conclusion and recommendation}

The air quality in the vicinity of two schools: one governmental and the other private school have been assessed for a period of four weeks using KISR's Mobile Air Quality Monitoring Station. It is found that the air quality in the vicinity of both schools is not adequate for the children due to high levels of non methane hydrocarbon almost all the times above the Kuwaiti EPA limit and also high $\mathrm{NO}_{2}$ levels showing exceedence sometimes. These pollutants are mainly due to oil related activities, oil production, refineries and other petrochemical industries, power station, fuel pumping stations, road traffic etc. It is important to maintain high standards of air quality around the schools in order to reduce the effect of traffic pollutants on health of children and their performance. High levels of pollution and traffic conjunctions are recognized as health risk. The Kuwait government should consider public transportation for the governmental schools students to abate traffic conjunction and associated air pollution problems in the country. 


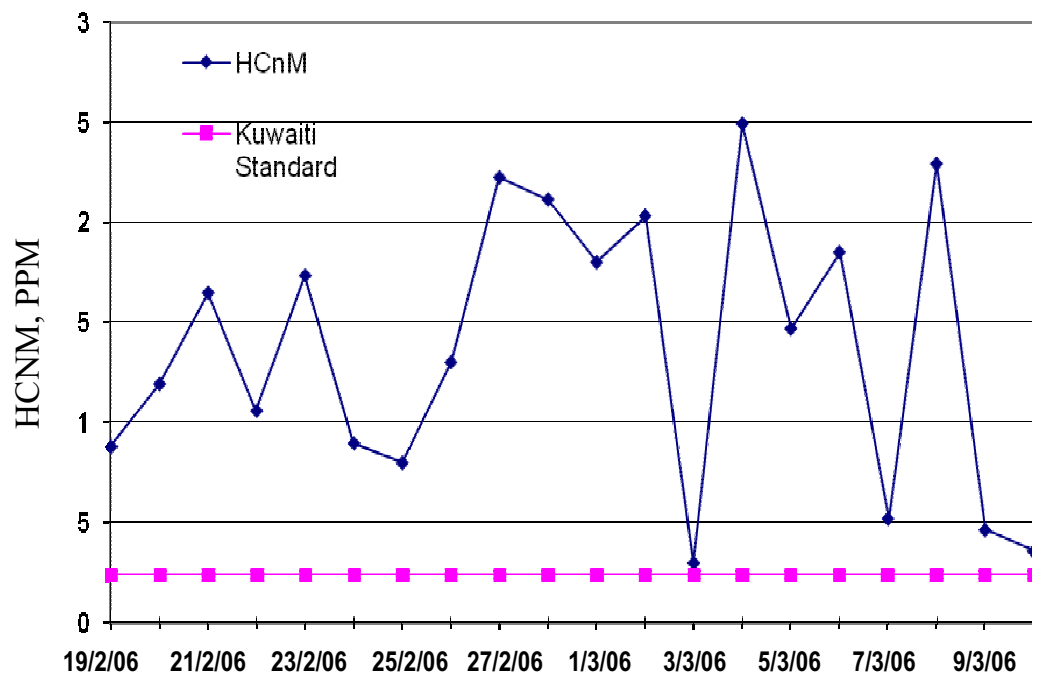

Days

Figure 9: Daily variation of the measured non-CH4 hydrocarbon around the private and government schools compared to Kuwaiti standards.

\section{References}

[1] Air quality expert group, 2007. "Air quality and climate change-UK Perspective Summery". Published for Environment, Food, and Rural Affairs; Scottish Executive: Welsh assembly Government and Department of the Environment in North Ireland. Crown copyright 2007.

[2] Uwe Lahl, Wilhelm Steven, 2005, "Traffic guidance and restrictionsLegally permissible options for air quality control policy". Federal Ministry for the Environment, Nature Conservation and Nuclear Safety (BMU), Bonn, Germany.

[3] G. D'Amato, G. Liccardi, M. D'Amato and M. Cazzola, 2002. European Respiratory Journal, 2002; 20:763-776.

[4] BBC NEWS. Health: Medical notes. "Exhaust emissions". 6 May, 1999.

[5] Guo,Y.L. et al., 1999. Climate, traffic-related air pollutants, an asthma prevalence in middle-school children in Taiwan. Environ Health Prospect, 107(12):1001-6.

[6] Al-Kuwait Al-Youm. 2001. Annexure No. 533, 2 October 2001, year 47. Ministry of Information (Arabic). 